\title{
Saturated Nucleate Boiling with HFE-7100 on a Plain Smooth Copper Surface
}

\author{
Xiaoguang Fan'1 ${ }^{1}$, Mohamed M. Mahmoud ${ }^{2,3}$, Atanas Ivanov $^{2}$, Tassos G. Karayiannis ${ }^{2}$ \\ ${ }^{1}$ Shenyang Agriculture University \\ 120 Dongling Rd. Shenhe District, Shenyang, China \\ xiaoguangfan1982@syau.edu.cn \\ ${ }^{2}$ Brunel University London \\ UB8 3PH, London, UK \\ mohamed.mahmoud@brunel.ac.uk; atanas.ivanov@brunel.ac.uk; tassos.karayiannis@brunel.ac.uk \\ ${ }^{3}$ Faculty of Engineering, Zagazig University, Zagazig, Egypt, 44519 \\ mbasuny@zu.edu.eg
}

\begin{abstract}
Pool boiling is one of the main modes of heat transfer in many industrial applications. Therefore, the pool boiling heat transfer performance of various surfaces/geometries and the establishment of reliable predictive correlations has received a lot of attention from laboratories across the world. Visualization and heat transfer measurements of pool boiling using hydrofluoroether HFE-7100 as the working fluid on a plain smooth copper surface are described in this paper. The polished boiling surface had an average surface roughness of $0.019 \mu \mathrm{m}$. The saturated pressure ranged from 0.7 to 2 bar. The saturation pressure was found to affect the number of active bubble nucleation sites at a given temperature difference between the wall and the saturation temperature, delayed the formation of bigger bubbles and affected the pool boiling heat transfer. Starting with the lower pressure of 0.7 bar, the heat transfer coefficient increased by an average of $24 \%, 49 \%$ and $60 \%$ for saturated pressure of $1.0,1.5$ and 2 bar respectively. The corresponding increase in the critical heat flux (CHF) was $27 \%, 48 \%$, and $64 \%$. The obtained experimental nucleate boiling heat transfer data as well as the CHF were compared with well-known correlations reported in the literature.
\end{abstract}

Keywords: Pool boiling, heat transfer coefficient, critical heat flux, saturated pressure, correlations.

\section{Introduction}

Pool boiling heat transfer is an efficient way of transferring high thermal loads in a variety of industries ranging from the power generation sector including nuclear plants to refrigeration plants, and at the smaller scales, to the cooling of electronic equipment. The initiation and establishment of the nucleate pool boiling regime and the triggering mechanism of critical heat flux (CHF) are complex processes and depend on a number of factors including the thermophysical properties of the fluid and the surface characteristics. This may explain the large number of correlations proposed by researchers to predict the boiling heat transfer coefficient and the CHF. The saturation pressure, which can be expressed as reduced pressure (ratio of operating pressure to critical pressure), affects both the nucleate boiling regime and the CHF through its effect on the fluid properties.

The effect of pressure on the pool boiling process was examined by a number of researchers. Rainey et al. [1] and Kwark et al. [2] investigated the effect of system pressure on the saturated nucleate boiling curves of plain and finned surfaces using FC-72 [1] and surfaces coated with $\mathrm{Al}_{2} \mathrm{O}_{3}$ nano particles using water as the working fluid [2]. They found that the heat transfer coefficient and the CHF value increase with increasing pressure. Sakashita [3] carried out boiling experiments with water on horizontal and vertical surfaces at a pressure range of $0.35-5 \mathrm{MPa}$, and indicated that, for a fixed heat flux value, the number of active nucleation sites $(n)$ increased with increasing pressure $\left(n \alpha P^{1.5}\right)$. Sakashita and Ono [4] also used water and found that the diameter of the detached bubbles decreased with higher pressure, while the detachment frequency of coalesced bubbles was insensitive to the pressure. Wengler et al. [5] demonstrated that the heat transfer coefficient increased with increasing reduced pressure. This agreed with the results reported above by Rainey et al. [1] and Kwark et al. [2] and the results from Chen et al. [6] and Gorenflo et al. [7]. Similarly, Kalani and Kandlikar [8] and Mudawar and Anderson [9] conducted pool boiling experiments at sub-atmospheric and moderately high pressures, respectively. Their results showed that the pool boiling heat transfer performance improved with increasing system pressure. The excess temperature (the 
difference between wall and saturation temperature) for a given heat flux was lower at higher pressure. Dahariya and Betz [10] studied the effect of pressure on the heat transfer performance during pool boiling using water on a smooth copper surface, and pointed out that increasing the pressure not only changed the hydrodynamic behaviour, but also impacted the formation of the thermal boundary layer. They also noted that the heat transfer enhancement with different pressures was more significant at higher heat flux.

The effect of pressure on the CHF of HFE-7100 was investigated by Alvariño et al. [11] on differently roughened surfaces. Their experimental results demonstrated that the CHF increased with pressure. In addition, they reported that the dependence of $\mathrm{CHF}$ on surface roughness was more pronounced when the system pressure was increased. As mentioned above, a number of correlations have been reported in the literature to predict the nucleate boiling heat transfer coefficient and the CHF. In general, the following factors are reported and included in the correlations influencing the nucleate boiling heat transfer and the CHF: thermophysical properties of working fluids, surface characteristics, wettability, base material, heat flux, surface orientation and system pressure.

The pool boiling characteristics of hydrofluoroether dielectric fluid HFE-7100 (methoxy-nonafluorobutane (C4F9OCH3)) are reported in this study. This fluid has wide applications in industry as a heat transfer fluid and as a spray contact cleaner. This is due to its low global warming potential (GWP 320), zero ozone depletion potential, chemical and thermal stability, high wettability, low toxicity and the fact that it is non-flammable [12]. Experiments were conducted at four different pressures of 0.7 bar, 1 bar, 1.5 bar and 2 bar on a horizontal boiling surface with an average roughness of $0.019 \mu \mathrm{m}$. The values were compared with existing correlations in order to make recommendations for design.

\section{Experimental setup and procedure}

\section{1. Experimental apparatus and method}

The experimental facility, seen in Figure 1, consists of a copper block, a boiling chamber with auxiliary heater, a vapour condenser, a water/R-134a heat exchanger and the R-134a cooling system. Saturated vapour produced on the boiling surface enters the condenser unit, with the condensate returning to the boiling chamber by gravity via a filter. Deionized water was used as cooling medium in the condenser. This was cooled in the heat exchanger using an R-134a vapour compression refrigeration unit. The boiling chamber was a vertical stainless steel 304 cylinder of inside diameter $22 \mathrm{~cm}$ with two circular glass windows mounted on its sides for visualization. A pressure transducer and three thermocouples were used to monitor the saturation state of the working fluid in the chamber. The chamber was thermally insulated and has a $1250 \mathrm{~W}$ auxiliary heater rubbed between the rubber insulation and the chamber to help maintain system saturated conditions. Heating was provided by six $250-\mathrm{W}$ cartridge heaters $10 \mathrm{~mm}$ in diameter, which were installed in the lower part of the cooper heater block, see figure 1. The heat input was regulated using a variable transformer and measured by a power meter. Six type-K thermocouples were inserted in the center of the copper block, $5 \mathrm{~mm}$ apart in the vertical direction to help calculate the heat flux to the boiling surface. The test surface was the upper surface of a disk, $40 \mathrm{~mm}$ in diameter and $5 \mathrm{~mm}$ high placed on top of the copper block. A K-type thermocouple was inserted in a $1.5 \mathrm{~mm}$ diameter hole, $15 \mathrm{~mm}$ deep, located $2.25 \mathrm{~mm}$ from the top surface to facilitate the calculation of the surface temperature. Solder was used to maintain good thermal contact between the bottom surface of the disk and the top surface of the copper block.

The boiling smooth copper surface was prepared using a diamond turning machine (Nanotech 250UPL). The surface characteristics were then studied using a Scanning Electron Microscope, 3D optical surface profilometer. An in-house contact angle meter was used to record the static contact angle of HFE-7100 on the copper surface. The static contact angle $\theta$ was around $9^{\circ}$, see figure 2. The average surface roughness, $R a$, was $0.019 \mu \mathrm{m}$. The average value of the length of the profile element along the sampling length, $R s m$, was $8.73 \mu \mathrm{m}$ and the root mean square of the surface feature heights, $\mathrm{Rq}$, was of $0.024 \mu \mathrm{m}$.

The experimental system was tested for leaks and was degassed before starting the experiments. All the experimental data were recorded after the system reached steady state. Steady state was confirmed when the system pressure and heat flux remained stable for 10 minutes (i.e. the temperature and pressure did not change by more than $1.5 \mathrm{~K}$ and $3 \mathrm{kPa}$ respectively). Tests were performed at $0.7,1,1.5$, and 2 bar system pressure. Saturated conditions were achieved by adjusting the flow and inlet temperature to the condenser and the electric input to auxiliary heater. Experimental data were obtained for both increasing and decreasing heat flux, from nucleate boiling up to the critical heat flux. 


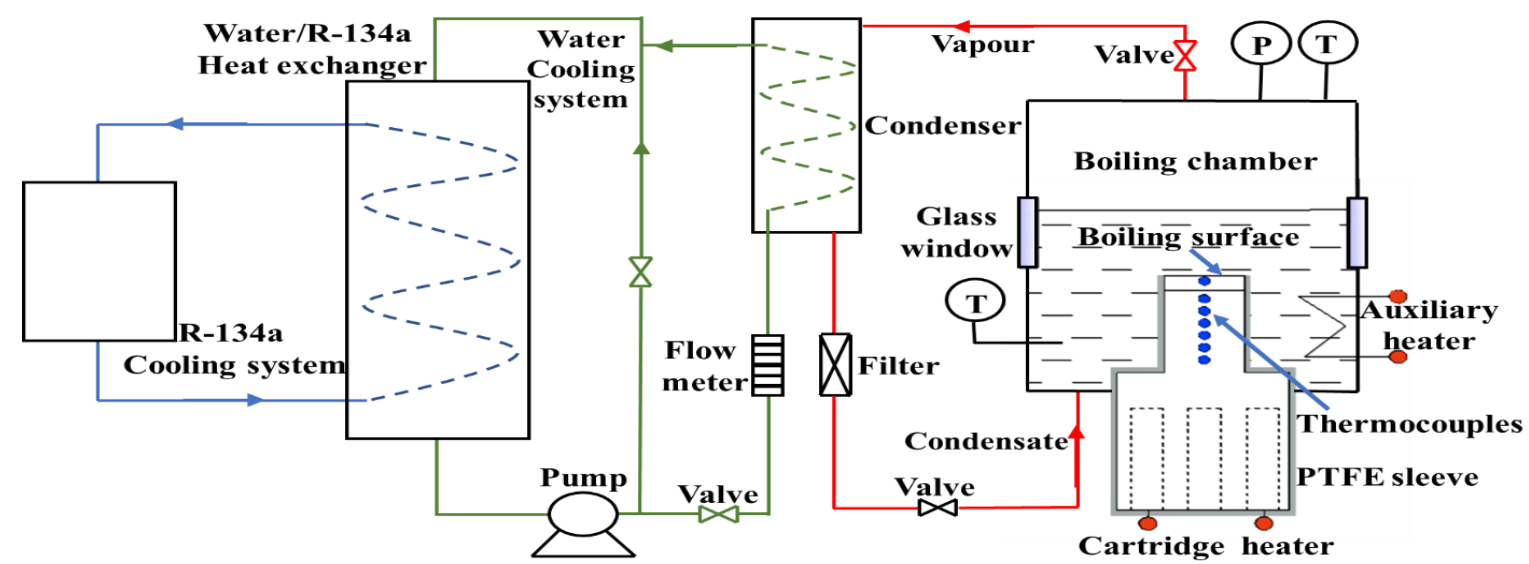

Fig. 1: Schematic diagram of experimental facility.

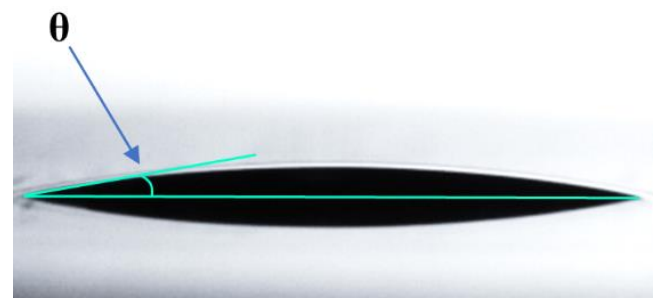

Fig. 2: Contact angle image of HFE-7100 on the smooth copper surface at $\mathrm{T}=20^{\circ} \mathrm{C}$.

\section{2. Data reduction}

In this study, six thermocouples were used to measure the temperature profile in the copper block. The temperature gradient was then used to calculate the heat flux $(q)$ as follows:

$$
q=\left.k_{c u} \cdot \frac{d T}{d y}\right|_{y=0}
$$

where $k_{c u}$ is the thermal conductivity of copper block, dT/dy $\left.\right|_{\mathrm{y}=0}$ is the vertical temperature gradient at the top surface of the disc. The heat transfer coefficient $(h)$ at the boiling surface can then be calculated as followed:

$$
h=\frac{q}{\left(T_{W}-T_{\text {sat }}\right)}
$$

where $T_{\text {sat }}$ is the fluid saturation temperature obtained from the thermocouples immersed in the liquid region. $T_{W}$ is the temperature of the boiling surface and can be calculated as:

$$
T_{W}=T_{d i s c}-\frac{q \cdot b}{k_{c u}}
$$

$T_{\text {disc }}$ is the measured temperature of copper disc, $b$ is the distance between the boiling surface and the thermocouple located in the copper disc $(b=2.25 \mathrm{~mm})$.

System calibration was first performed to ensure the reliability of experiments. The thermocouples were calibrated using a platinum resistance thermometer and their uncertainty was $\pm 0.1 \mathrm{~K}$. The pressure transducers were also calibrated using a dead weight pressure gauge tester (Bryans Aeroquipment LTD, with a range of atmospheric pressure to $3 \mathrm{bar}$ ) within $2 \mathrm{kPa}$. An error propagation analysis was performed, see [13]. The calculated uncertainty in the heat flux was between $0.7 \%$ and $5.9 \%$ and for the heat transfer coefficient was between $0.9 \%$ and $6.5 \%$. 


\section{Experimental results and discussion}

Typical pool boiling images were obtained for similar heat flux values at the four pressures examined in this study as seen in figure 3. At low heat flux, isolated bubbles were produced from the active cavities and departed without coalescing with other bubbles. The effect of pressure was obvious at small heat flux values. As seen in the figure, at a heat flux value of approximately $6 \mathrm{~kW} / \mathrm{m}^{2}$, increasing the pressure resulted in an increase in the number of active nucleation sites. This is due to the fact that the range of possible active cavity sizes increases with increasing saturation pressure, see Dahariya, and Betz [10] and Hsu [14]. Bubble coalesce was obvious as the heat flux increased. With further increases in heat flux, vapour columns or jets were formed and merged together.
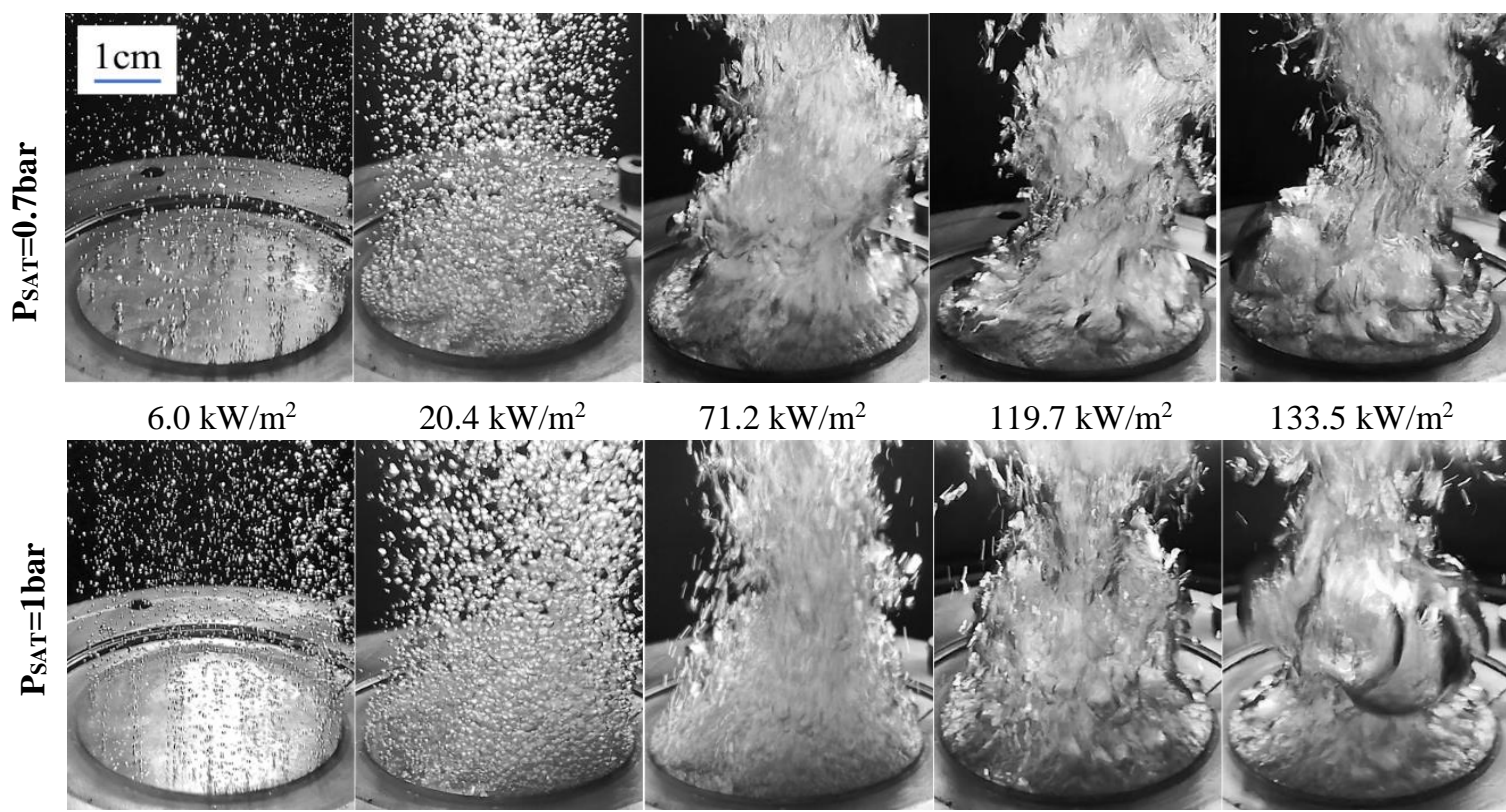

$71.2 \mathrm{~kW} / \mathrm{m}^{2}$

$119.7 \mathrm{~kW} / \mathrm{m}^{2}$

$133.5 \mathrm{~kW} / \mathrm{m}^{2}$
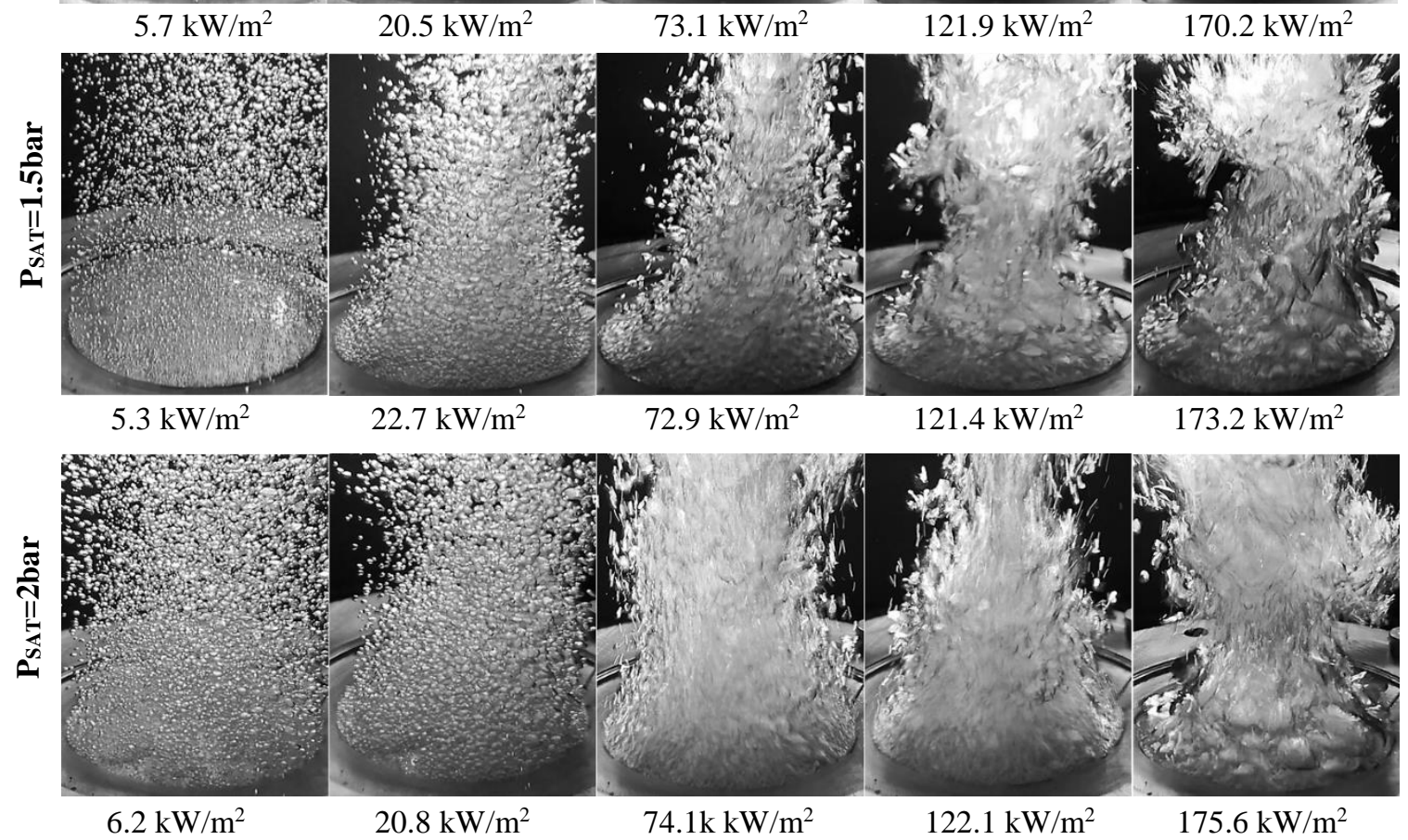

Fig. 3: Pool boiling images at different heat flux and saturated pressure. (The last photographs are near CHF and it was sometimes necessary to stop the experiments; hence the $135.5 \mathrm{~kW} \mathrm{~m}^{-2}$ at $\mathrm{P}=0.7 \mathrm{bar}$.) 
The boiling curves for HFE-7100 are depicted in Figure 4. The experimental results shown are for increasing heat flux. Boiling hysteresis was examined and the results demonstrated that for this surface and fluid the hysteresis was not significant and mostly within the experimental error of our data. The effect of pressure on the heat transfer rates is obvious. Both the heat transfer coefficient and the critical heat flux increased with increasing pressure. The heat transfer coefficient increased by an average of $24 \%, 49 \%$ and $60 \%$ respectively when the pressure was increased from 0.7 bar to $1,1.5$ and 2 bar. The corresponding CHF increased by $27 \%, 48 \%$, and $64 \%$. The effect of pressure may be attributed to the increase in the nucleation site density and the changes in bubble dynamics. As mentioned above, with reference to figure 3 , the range of possible active nucleation sites increases with increasing saturation temperature or pressure (see Hsu [14]), resulting in more nucleation sites on the heating surface. In addition, the bubble departure frequency increases and the bubble detachment diameter decreases with increasing saturation pressure as reported by $[10,15]$, which results in more bubbles being generated and hence higher heat transfer rates.

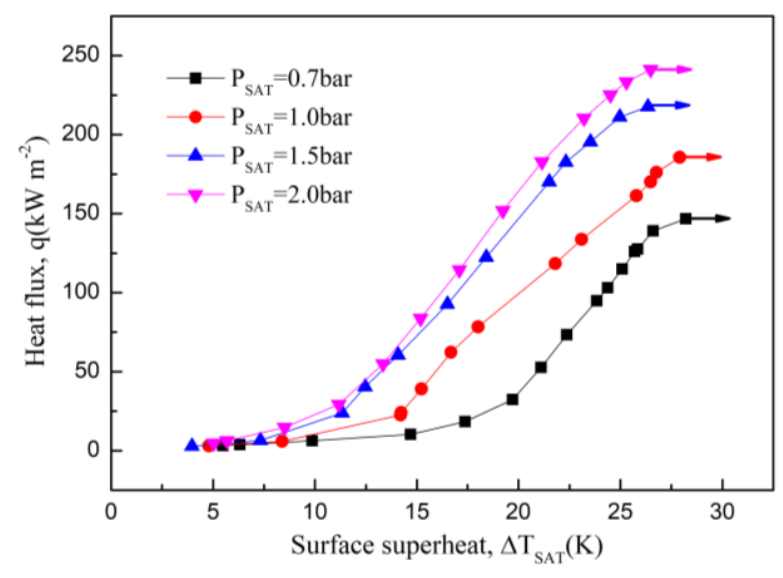

a)

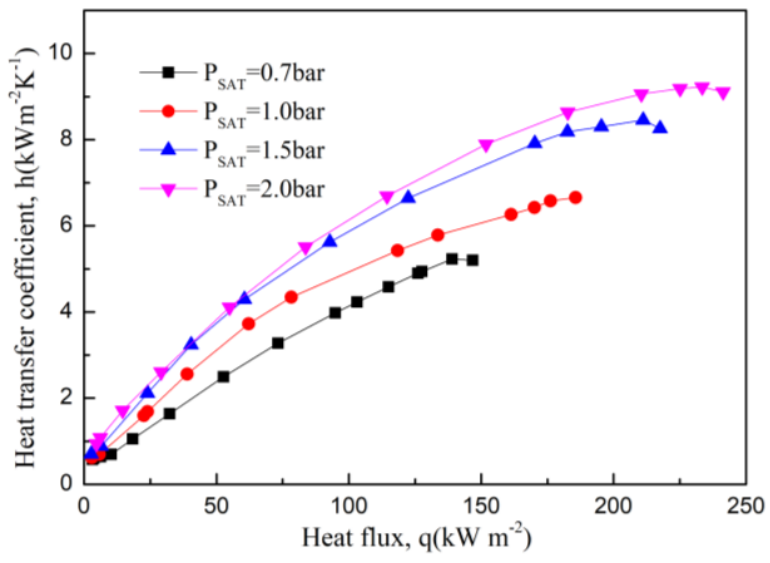

b)

Fig. 4: Boiling curves for HFE-7100: (a) heat flux versus wall superheat, (b) heat transfer coefficient versus heat flux.

There are currently a significant number of correlations predicting the boiling heat transfer coefficient and the critical heat flux [16-51]. Correlations given in references [16-33] for the nucleate boiling regime were assessed in this study predicting the boiling heat transfer coefficient for HFE-7100 with a mean absolute deviation ranging from $13.8 \%$ to $752.5 \%$. The current results for the critical heat flux were compared with the correlations described in references [34-51] and the mean absolute deviation ranged from $4.6 \%$ to $332.7 \%$. Parameters such as the fluid thermophysical properties, the contact angle and the surface roughness would impact the performance of these correlations significantly. Figure 5 depicts only the correlations that could predict the current data with a reasonable accuracy. As seen in the figure, the correlations of Forster and Zuber [17] predicted the heat transfer coefficient data reasonably well. The mean absolute deviation in the comparison with the Foster and Zuber correlation [17] ranged between $11.8 \%$ and $21.3 \%$ for all the pressures studied.

The critical heat flux comparisons are seen in figure 6. As depicted in the figure, the predicted results for Guan et al. [40], Kutateladze [35], Kim et al. [50], and Bailey et al. [44] were in good agreement with the critical heat flux values at 0.7 bar, 1 bar, 1.5 bar and 2 bar respectively. On the whole, the correlation by Guan et al. [40] can predict the current data on $\mathrm{CHF}$ more accurately, with the absolute deviation ranging from $3.2 \%$ to $5.5 \%$ for all the operating pressures.

\section{Conclusions and further work}

Pool boiling of HFE-7100 on a plain smooth copper surface under four different pressures 0.7, 1.0, 1.5 and 2.0 bar was presented in this study. The experiments covered the entire boiling curve, from convection to bubble initiation, nucleate boiling and critical heat flux. The conclusions that can be drawn from these first set of experimental results and comparisons with correlations are as follows:

(1) Saturation pressure can affect the number of active bubble nucleation sites. The presence of large bubbles was less evident at high pressure. 
(2) Saturation pressure had an obvious impact on the pool boiling heat transfer rates. The average increase in the heat transfer coefficient was $24 \%, 49 \%$ and $60 \%$ respectively when the pressure was increased from 0.7 bar to $1,1.5$ and 2 bar. The CHF increased by $27 \%, 48 \%$, and $64 \%$ for this range of pressure.

(3) The present heat transfer coefficient results compared well with the predictions by Forster and Zuber [17] for the entire pressure range covering sub-atmospheric pressure of 0.7 bar to 2.0 bar. The CHF correlation of Guan et al. [40] predicted well the current results.

The effect of surface roughness on the contact angle, regimes, heat transfer coefficient and $\mathrm{CHF}$ at different pressures is currently being examined. Comparative results will be presented at the meeting.
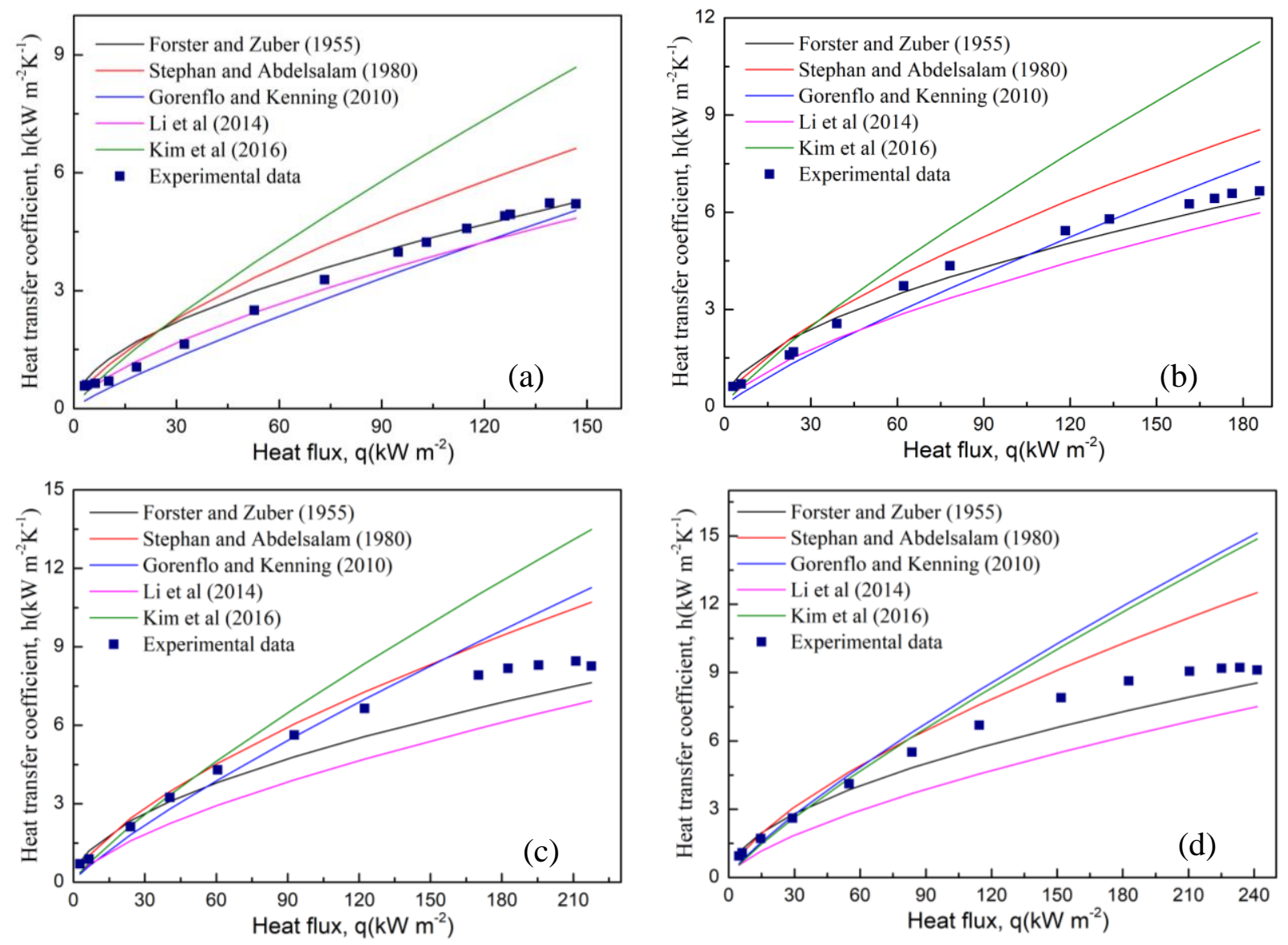

Fig. 5: Comparison of experimental heat transfer coefficient results with correlations:

(a) $\mathrm{P}_{\mathrm{SAT}}=0.7 \mathrm{bar}$, (b) $\mathrm{P}_{\mathrm{SAT}}=1$ bar, (c) $\mathrm{P}_{\mathrm{SAT}}=1.5 \mathrm{bar}$, (d) $\mathrm{P}_{\mathrm{SAT}}=2 \mathrm{bar}$. 


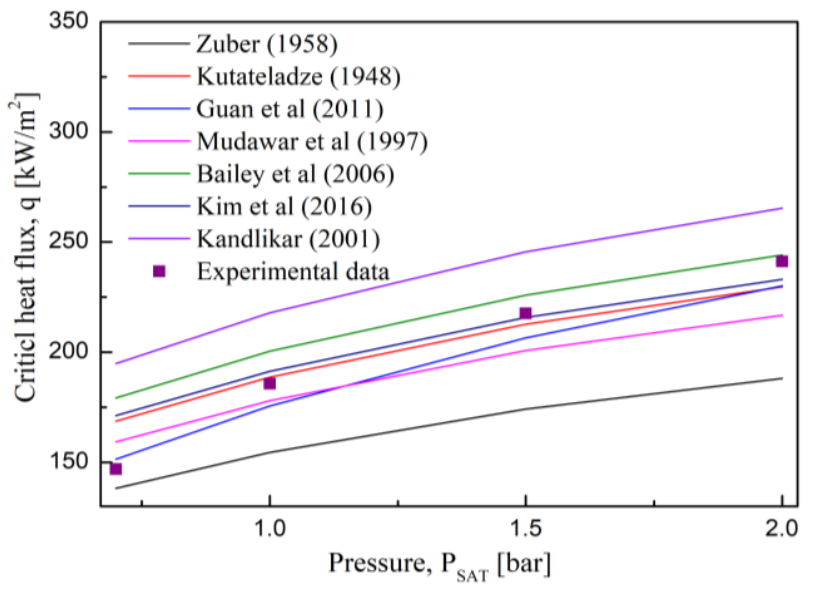

Fig. 6: Comparison of experimental critical heat flux results with correlations.

\section{References}

[1] K. N. Rainey, S. M. You, S. Lee, "Effect of pressure, subcooling, and dissolved gas on pool boiling heat transfer from microporous, square pin-finned surfaces in FC-72," Int. J. Heat Mass Transfer, vol. 46, no. 1, pp. 23-35, 2003.

[2] S. M. Kwark, M. Amaya, R. Kumar, G. Moreno, S. M. You, "Effects of pressure, orientation, and heater size on pool boiling of water with nanocoated heaters," Int. J. Heat Mass Transfer, vol. 53, no. 23-24, pp. 5199-5208, 2010.

[3] H. Sakashita, "Bubble growth rates and nucleation site densities in saturated pool boiling of water at high pressures," J. Nucl. Sci. Technol., vol. 48, no. 5, pp. 734-743, 2011.

[4] H. Sakashita, A. Ono, "Boiling behaviors and critical heat flux on a horizontal plate in saturated pool boiling of water at high pressures," Int. J. Heat Mass Transfer, vol. 52, no. 3-4, pp. 744-750, 2009.

[5] C. Wengler, J. Addy, A. Luke, "Experimental investigation of heat transfer of R134a in pool boiling on stainless steel and aluminum tubes," Heat Mass Transfer, vol. 55, no. 1, pp. 59-66, 2019.

[6] H. Chen, G. Chen, X. Zou, Y. Yao, M. Gong, "Experimental investigations on bubble departure diameter and frequency of methane saturated nucleate pool boiling at four different pressures," Int. J. Heat Mass Transfer, vol. 112, pp. 662-675, 2017.

[7] D. Gorenflo, U. Chandra, S. Kotthoff, A. Luke, "Influence of thermophysical properties on pool boiling heat transfer of refrigerants," Int. J. Refrigeration, vol. 27, no. 5, pp. 492-502, 2004.

[8] A. Kalani, S. G. Kandlikar, "Enhanced pool boiling with ethanol at subatmospheric pressures for electronics cooling," J. Heat Transfer, vol. 135, no. 11, pp. 111002, 2013.

[9] I. Mudawar, T. M. Anderson, "Parametric investigation into the effects of pressure, subcooling, surface augmentation and choice of coolant on pool boiling in the design of cooling systems for high-power-density electronic chips," Lect. Notes Math., vol. 843, no. 6, pp. 366-372, 1990.

[10] S. Dahariya, A. R. Betz, "High pressure pool boiling: Mechanisms for heat transfer enhancement and comparison to existing models," Int. J. Heat Mass Transfer, vol. 141, pp. 696-706, 2019.

[11] P. F. Alvariño, M. L. S. Simón, M. dos Santos Guzella, J. M. A. Paz, J. M. S. Jabardo, L. C. Gómez, "Experimental investigation of the CHF of HFE-7100 under pool boiling conditions on differently roughened surfaces," Int. J. Heat Mass Transfer, vol. 139, pp. 269-279, 2019.

[12] S. J. Thiagarajan, R. Yang, C. King, S. Narumanchi, "Bubble dynamics and nucleate pool boiling heat transfer on microporous copper surfaces," Int. J. Heat Mass Transfer, vol. 89, pp. 1297-1315, 2015.

[13] R. J. Moffat, "Describing the uncertainties in experimental results," Exp. Therm. Fluid Sci., vol. 1, pp. 3-17, 1988.

[14] Y. Hsu, "On the size range of active nucleation cavities on a heating surface," J. Heat Transfer., vol. 84, pp. 207-213, 1962.

[15] A. Miglani, D. Joo, S. Basu, R. Kumar, "Nucleation dynamics and pool boiling characteristics of high pressure refrigerant using thermochromic crystals," Int. J. Heat Mass Transfer., vol. 60, pp. 188-200, 2013.

[16] W. M. Rohsenow, "A method of correlating heat transfer data for surface boiling of liquids," Trans. ASME, vol. 74, pp. 969-975, 1952. 
[17] H. Forster, N. Zuber, "Dynamics of vapor bubbles and boiling heat transfer," AIChE J., vol. 1, pp. 531-535, 1955.

[18] I. L. Mostinski, "Application of the rule of corresponding states for calculation of heat transfer and critical heat flux," Teploenergetika, vol. 4, no. 4, pp. 66-71, 1963.

[19] K. Stephan, M. Abdelsalam, "Heat transfer correlations for natural convection boiling," Int. J. Heat Mass Transfer, vol. 23, pp. 73-87, 1980.

[20] M. G. Cooper, "Heat flow rates in saturated nucleate pool boiling a wide ranging examination using reduced properties," Adv. Heat Transfer, vol. 16, pp. 157-239, 1984.

[21] D. Gorenflo, "H2 behältersieden (sieden in freier konvektion)," in VDI-Wärmeatlas, VDI-Buch, Springer Berlin Heidelberg, 1993, pp. 853-894.

[22] D. Gorenflo, D. Kenning, "H2-pool boiling," in VDI-Heat Atlas, Düsseldor: VDI-Verlag, 2010, pp. 757-792.

[23] G. Ribatski, J. M. Saiz Jabardo, "Experimental study of nucleate boiling of halocarbon refrigerants on cylindrical surfaces," Int. J. Heat Mass Transfer, vol. 46, pp. 4439-4451, 2003.

[24] J. M. Saiz Jabardo, E. Fockink da Silva, G. Ribatski, S. F. de Barros, "Evaluation of the rohsenowcorrelation through experimental pool boiling of halocarbon refrigerants on cylindrical surfaces," J. Braz. Soc. Mech. Sci. Eng., vol. 26, no. 2, pp. 218-230, 2004.

[25] E. Van Rooyen, F. Agostini, N. Borhani, J. Thome, "Boiling on a tube bundle: Part II-Heat transfer and pressure drop," Heat Transfer Eng., vol. 33, no. 11, pp. 930-946, 2012.

[26] D. Jung, H. Lee, D. Bae, S. Oho, "Nucleate boiling heat transfer coefficients of flammable refrigerants," Int. J. Refrigeration, vol. 27, pp. 409-414, 2004.

[27] Y. Y. Li, Y. J. Chen, Z. H. Liu, "A uniform correlation for predicting pool boiling heat transfer on plane surface with surface characteristics effect," Int. J. Heat Mass Transfer, vol. 77, pp. 809-817, 2014.

[28] W. H. Wang, F. Z. Wu, Q. B. Yu, H. X. Jin, "Experimental investigation of titanium tetrachloride in pool boiling heat transfer," Int. J. Heat Mass Transfer, vol. 122, pp. 1308-1312, 2018.

[29] I. S. Kiyomura, T. S. Mogaji, L. L. Manetti, E. M. Cardoso, "A predictive model for confined and unconfined nucleate boiling heat transfer coefficient," Appl. Therm. Eng., vol. 127, pp. 1274-1284, 2017.

[30] D. Jung, Y. Kim, Y. Ko, K. Song, "Nucleate boiling heat transfer coefficients of pure halogenated refrigerants," Int. J. Refrigeration, vol. 26, pp. 240-248, 2003.

[31] D. Robinson, J. Thome, "Local bundle boiling heat transfer coefficients on a plain tube bundle (RP-1089)," HVAC R Res., vol. 10, no. 1, pp. 33-51, 2004.

[32] D. A. Labuntsov, "Heat transfer problems with nucleate boiling of liquids," Therm. Eng., vol. 19, no. 9, pp. 21-28, 1972.

[33] J. Kim, S. Jun, R. Laksnarain, S. M. You, "Effect of surface roughness on pool boiling heat transfer at a heated surface having moderate wettability," Int. J. Heat Mass Transfer, vol. 101, pp. 992-1002, 2016.

[34] N. Zuber, "On the stability of boiling heat transfer," Trans. ASME, vol. 80, pp. 711-720, 1958.

[35] S. Kutateladze, "On the transition to film boiling under natural convection," Kotloturbostroenie, vol. 3, pp. 10-12, 1948.

[36] J. Lienhard, V. Dhir, "Extended hydrodynamic theory of the peak and minimum pool boiling heat fluxes," Technical Report, NASA CR-2270, 1973.

[37] L. Wang, Y. Li, F. Zhang, F. Xie, Y. Ma, “Correlations for calculating heat transfer of hydrogen pool boiling,” Int. J. Hydrogen Energy, vol. 41, pp. 17118-17131, 2016.

[38] W. M. Rohsenow, P. Griffith, "Correlation of maximum heat transfer data for boiling of saturated liquids," Chem. Eng. Prog. Symp. Ser., vol. 52, pp. 47-49, 1955.

[39] Y. Haramura, Y. Katto, "A new hydrodynamic model of critical heat flux, applicable widely to both pool and forced convection boiling on submerged bodies in saturated liquids," Int. J. Heat Mass Transfer, vol. 26, pp. 389-399, 1983.

[40] C-K. Guan, J. F. Klausner, R. Mei, “A new mechanistic model for pool boiling CHF on horizontal surfaces," Int. J. Heat Mass Transfer, vol. 54, pp. 3960-3969, 2011.

[41] I. Mudawar, A. H. Howard, C. O. Gersey, "An analytical model for near-saturated pool boiling critical heat flux on vertical surfaces," Int. J. Heat Mass Transfer, vol. 40, pp. 2327-2339, 1997.

[42] Y. A. Kirichenko, P. S. Chernyakov, "Determination of the first critical thermal flux on flat heaters," J. Eng. Phys. Thermophys., vol. 20, pp. 699-703, 1971.

[43] J. M. Ramilison, P. Sadasivan, J. H. Lienhard, "Surface factors influencing burnout on flat heaters," J. Heat Transfer, vol. 114, pp. 287-290, 1992. 
[44] W. Bailey, E. Young, C. Beduz, Y. Yang, "Pool boiling study on candidature of pentane, methanol and water for near room temperature cooling," in Thermal and Thermomechanical Phenomena in Electronics Systems, IEEE, San Diego, USA, pp. 599-603, 2006.

[45] R. I. Soziev, M. A. Khrizolitova, "Calculating critical heat flux density with pool boiling," Therm. Eng., vol. 37, pp. 400-401, 1989.

[46] V. M. Borishanskii, "On the problem of generalizing experimental data on the cessation of bubble boiling in large volume of liquids," Report No. Ts. K.I.T 28, Moscow, Soviet Union, 1955.

[47] S. G. Kandlikar, "A theoretical model to predict pool boiling CHF incorporating effects of contact angle and orientation," J. Heat Transfer, vol. 123, pp. 1071-1079, 2001

[48] L. Liao, R. Bao, Z. Liu, "Compositive effects of orientation and contact angle on critical heat flux in pool boiling of water," Heat Mass Transfer, vol. 44, pp. 1447-1453, 2008.

[49] A. Priarone, "Effect of surface orientation on nucleate boiling and critical heat flux of dielectric fluids," Int. J. Therm. Sci., vol. 44, pp. 822-831, 2005.

[50] S. J. Kim, I. C. Bang, J. Buongiorno, L. W. Hu, "Surface wettability change during pool boiling of nanofluids and its effect on critical heat flux," Int. J. Heat Mass Transfer, vol. 50, pp. 4105-4116, 2007.

[51] S. G. Liter, M. Kaviany, "Pool-boiling CHF enhancement by modulated porouslayer coating: theory and experiment," Int. J. Heat Mass Transfer, vol. 44, no. 22, pp. 4287-4311, 2001. 